\title{
Linguistic Reflections of Children's Transformation from Circadian to Newtonian Time and the Direction of Time
}

\author{
Mehmet OZCAN \\ Mehmet Akif Ersoy University, Faculty of Education, Foreign Language Education
}

\begin{abstract}
Both linguistically and conceptually, the acquisition of time by children is pretty late when the process is compared with the acquisition and usage of linguistic elements denoting objects, states, actions and situations. This study investigated how children transform their Circadian time to Bergsonian time and how they encode Newtonian time linguistically.

The study was carried out by the researcher's longitudinal observation of his three daughters from the ages 2 to 10 . In order to verify the idiosyncratic temporal production of the three children, cross-sectional data were also collected using a day organization test.

The results show that, (a) children between the ages of 3 and 4 live more in deictic time in that they refer to momentarily completed events such as a parent's or sibling's coming home or doing something which is worth mentioning from point of view of the child ("Baba geldi" 'Daddy is home.' or "düștü" '(it) fell'). (b) Children live in the Circadian time until the ages of 8-11 in that they conceive of and state time with reference to zeitgebers such as sleep-wake or day-night cycles. They also live simultaneously in Bergsonian time in that they refer to temporal units (e.g. days) with reference to the closest temporal unit (e.g. Dünden sonra" "The day dfter yesterday' to mean the day before yesterday and "Yarından sonra" "The day after tomorrow". (d) They begin to adopt Newtonian time with reference to certain successive events such as "Two days earlier" and then refine their conceptualization of Newtonian time by referring to hours (but not minutes). (e) Children are pretty ahead of Newtonian time in the construction of complex temporal relations linguistically.
\end{abstract}

Keywords: conceptualization of time, temporal development, Circadian time, Bergsonian time, Newtonian time

\section{Introduction}

The question whether time exists or what it is has been debated for centuries in philosophy. In the scientific field, its existence has well been admitted since many equations in physics have been constructed by taking time as a factor. Another question to be answered related to time is whether human beings have a sense of time to determine the point and duration of time without reference to spatiotemporal displacements, that is, lawfulness and causality in nature or human artifact. Although no results showing the existence of an innate capacity to sense measurable time have been revealed to date, there are studies conducted to investigate how the concept of time is constructed by newborns and infants. Piaget is one of the most celebrated of these scholars. $\mathrm{He}$ raised two fundamental questions concerning time and space upon Einstein's questioning of time whether our intuitive grasp of time is primitive or derived and its relation with velocity at a conference (Piaget, 1969:87-88; Sauer 2014). Rather than finding the exact answer to the question, Piaget observed his own children and experimented to grasp how children conceive of time. At early ages of the children Piaget observed how they behave in an environment where sequential events take place and he came up with conclusions about the construction of the concepts of 'before' and 'after'. At later ages, 
he exposed children to conditions in which they had to set relationship between motion, velocity and distance. He moved a toy car from point A to point $B$ and another from point $D$ to point $E$ simultaneously but each car having different velocity and asked questions about the length of time and distance to children at different ages. We are not going to detail the experiments here since details related to experiments can be found in his book. The thing we are concerned with these experiments is that the intuitive time cannot be tested without relating it to a motion at micro level and to an event, state or action at macro level. If it cannot be tested without being related to other things, what is time? There are two basic evaluations of time in relation to the sensor: Time is in us and we are in time. While time is in us in circadian, Bergsonian and psychological understanding of time, Newton places us into time since it cannot be sensed at all: who can tell you that 'exactly forty eight minutes fifteen seconds past' by closing her/his eyes if the person does not make use of time measuring devices?

\subsection{Circadian and circannual time (clock)}

Circadian and circannual time is the concept of time which is constructed on the bases of frequency. This frequency may be the frequency of the actual act of sucking milk from breast or mother's holding the baby to nurse it at intervals or the sun's recurring rise in the east or, seasons' observable change in nature. Months, and weeks do not exist in this type of time whereas day do because of the daytime and nighttime shift. Biological clock, which is triggered by our basic physiological needs is also considered to be within circadian time (See Johnsson, 2008). If it is within approximately 24 hours, it is called circadian (from Latin, circa+dian, about+day: almost one day) and if it covers one year it is called circannual (from Latin circa+annual, about+year: almost one year).

\subsection{Bergsonian time}

Bergsonian time is not divided into periods. Instead, it is the concept of time which runs like a river does.
We do not know the beginning and the end of it. We are always at the deictic now of this time. Long term changes such as "How grown up your kids have become! They were in short pants when I saw them last time" type of astonishment makes us feel the existence of Bergsonian time.

\subsection{Psychological (intuitive) time}

Psychological time refers to a specific duration which is sensed according to the special condition of the sensor. Its realization is totally depends on the related things. In situations we expect something pleasing or frightful, the duration is conceived longer than the same duration we spend while doing something very enjoyable (Barnes \& Jones, 2000; James, 1890; Myers, 1971). The saying 'A watched pot never boils.' explains it pretty well.

\subsection{Newtonian time}

Newtonian time is the measurable time imposed by Newton. He divided time into seconds, minutes, hours, days, weeks, months, years, centuries and millennia in order to organize life on the bases of measurement (e.g. two weeks) or temporal points (e.g. at five o'clock).

\subsection{Entropy: The direction of time}

One of my daughters (Şerife), when she was around the age of 10, had said "Daddy, if I am to concretize God in my mind, I would think of time because time is impregnable, omnipresent and changes everything but we can do nothing to time. What disturbs me is that I do not know what time is." Neither do scientists. The term entropy is explained within the second law of thermodynamics. While the first law states that energy cannot be created or destroyed but it can transform from one form into another, the second law proposes that energy in closed systems moves from an ordered state to a disordered one unidirectionally. Though this movement itself is not time, this disorder, that is, entropy, enables us to sense time by the continuous change (See Rifkin and Howard, 1980:20).

1.6 The sense and conception of time in human beings 
It is not random that most of the personal narratives and stories begin with the opening utterance "One day, ..." or "In a stormy night, ..." or the like. This opening utterance usually is anchored to a landmark event or state and the construction of the story would be around this landmark. So, time of other events in the story is constructed according to the strength of their relation or distance to the landmark event. Koriat (1974) studied how adults retrieve days and he asked the question "What day is today?" and found that the mistake related to the retrieval of days was curvilinear; the participants made more mistakes with the retrieval of the days Wednesday and Thursday which are further in time to the past and forthcoming weekends. Future plans have also a strong impact on the retrieval of days. A person who is to pay a big amount of money on a certain day relates the approaching days to this payday. So this person constructs her/his own idiosyncratic days map which must be different from the map of the days of the week (Jonas \& Huguet, 2008).

How children conceive of time and how they reflect it in their language differs from the way adults conceive of and use time to organize their daily life. While children make use of cyclic occurrences in their environment to construct a temporal location for a specific event or state at younger ages (DroitVolet \& Rattat, 1999; Johnsson, 2008; Glickman, 2010; Montangero, 1996), they attempt to grasp the Newtonian time in later ages. First, children learn verbal recitation of these temporal divisions and then their image representations interfere with their concept of Newtonian time (Freidman, 1983; Freidman, 1984; Freidman, 1986; Keil, 1984; McCormack \& Hoerl, 2017; Shanon, 1979).
The aim of this present study is to investigate how children transform their Circadian time to Bergsonian time and how they encode Newtonian time linguistically and how they conceive of the direction of time.

\section{Methodology}

The study was carried out by the researcher's longitudinal observation of his three daughters from the ages 2 to 10 . The longitudinal data were collected by taking notes of the utterances produced by children. Notes were taken immediately after they produced it in order to preserve the originality of the production. Familial environment voice or video recordings were scanned and parts which contain time related utterances were transcribed for analysis. The transcribed utterances were analyzed qualitatively with reference to the concept of time.

Along with occasionally emerging, idiosyncratic temporal production of the three children, crosssectional data were also collected to test children's understanding of the direction of time. Participants of this test were children from the age of 4 to 10 as 10 participants in each age group.

We drew a table containing five cells. The cell in the middle contains the silhouette of a human head and others containing hearts in different colors. We did not use any orthographic marker since Turkish writing system runs from left to right just as English written words do. Thinking that the direction of the running of the letters in a word would impose a sense of directionality which would be a factor in the child's identification of 'backward' and 'forward' movement.

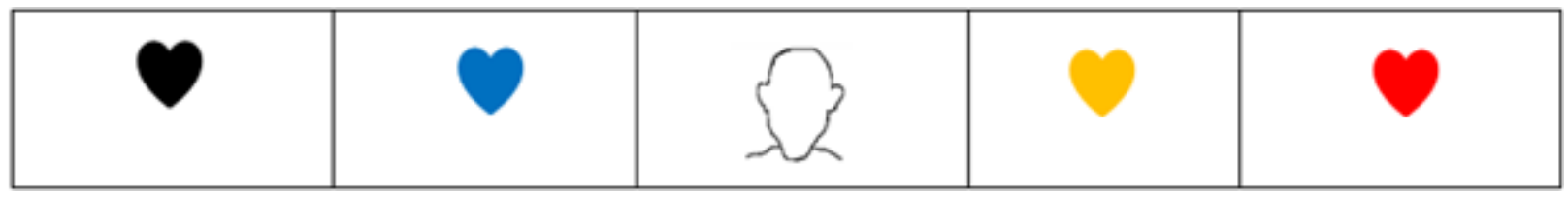

Figure 1: The picture to test the order of days in children's conceptualization

We instructed children in the following way: "Look. These boxes are days. You are in the box you see a head. That box is today." We checked whether they understood the explanation and clarified in cases 
they could not. Then we asked the following questions: "If the box you are in is today, how would you call the day with the blue heart?" Then "How would you call the day with the black heart?", then "If the box you are in is today, how would you call the day with the yellow heart? and finally, "How would you call the day with the red heart?

The data elicitation from children was videorecorded and then transcribed. The transcribed data were analyzed both qualitatively and quantitatively to find out the frequencies for each age group.

\section{Findings}

Our observations showed that children between the ages of 2 and 4 live more in deictic time in that they refer to momentarily completed events such as a parent's or sibling's coming home or doing something which is worth mentioning from point of view of the child ("Baba geldi" 'Daddy is home.' or "düştü" '(it) fell').

\subsection{Findings related to the direction of time}

The longitudinal data rendered strong clues showing that children conceive of time as flowing both towards forward (towards the direction we face) and backward. Since the longitudinal data emerged occasionally, this study is not in a position to present systematic change regarding the age groups. They will be presented age-incrementally.

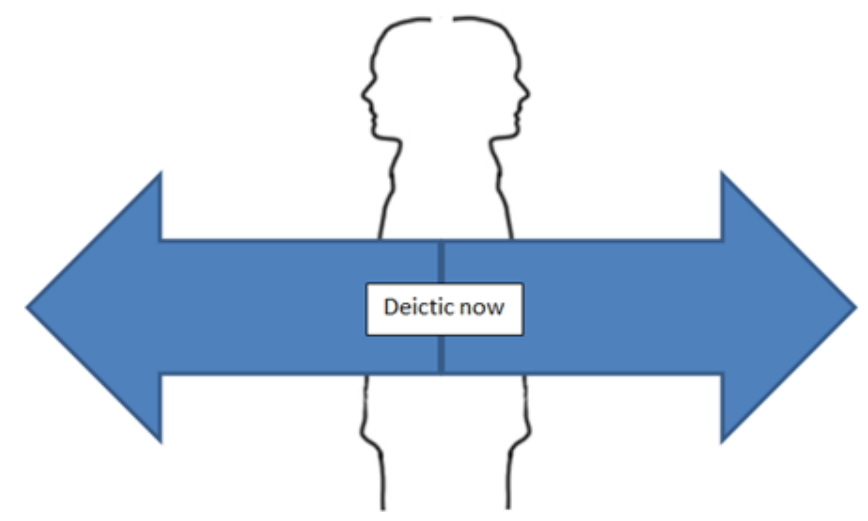

Figure 2: The direction of time from children's point of view; time flows towards both past and future.
(1)

Şerife (03:06f)

Şerife-Daddy, come, the Toy Story in our CD is also on TV.

Me-Where? (The scene had disappeared)

Şerife-It was there, on TV. I had seen it some time later.

In Turkish, 'biraz sonra' is the counterpart of 'some time later' which refers to a later time in future than the time of the utterance. However the child uses this expression to refer to a certain time which is, according to adult conception, earlier than the time of the utterance. The same referencing emerged in (2), (3), (4), (5) and (6) recurrently, on which we are not going to speculate.

(2)

Beril (04;10f) (My third daughter)

-Daddy did you hear a rattling sound some time later? It was me.

Şerife (05:08f)

We are going to eat fried cauliflower at dinner. Şerife asked me when she saw the meal.

Şerife-Daddy, what does 'yesterday' mean?

Me - The day before today.

Şerife-You mean, it is the day we left behind?

Me - Yes

Şerife-Daddy, do you know, the yesterday of yesterday, there was a recipe on TV. They had cooked this meal.

Elif $(05 ; 12 \mathrm{f})$

Elif could not remember the name of the shop we bought something two days ago and asked me. -Daddy, what is the name of the shop we went the day after yesterday?

Beril (04;09f)

Daddy, how many more years have we been using this camera? 
Turkish: Kaç yıl daha > English: how many more years.

'How many more years' requires a future temporal point such as 'will we use/are we going to be using'. The future temporal point in adults seems to have the same futureness towards past in the child's time concept. The protocol (7) testifies this very strongly.

\section{(6)}

\section{Elif (06;06f)}

Elif is asking Şerife whether she remembers the dance which she $(E)$ is performing.

Elif-Şerife, do you remember this? We had rehearsed yesterday.. no.. no.. the day after yesterday.

dün-den sonra

yesterday-ABL after

'the day after yesterday'

\section{(7)}

Şerife (05:03f) saw a pair of old shoes of mine which she had never seen before. She asked:

Şerife-Daddy, whose are these?

Me- They are mine, darling.

Şerife-Why haven't I seen them so far?

Me- They are rather from old times.

Şerife- You mean, mom and you had got married and you bought them after we had not born?

(Turkish: Yani, siz annemle evlenmiştiniz de biz doğmadıktan sonra mı almıştın?)

doğ-ma-dik-tan sonra

Born-NEG-PAST-ABL after

After we had not born

In (7) the five-year-old child constructs a very complicated temporal structure; she takes the mother and father's marriage as the landmark event, then she positions their birth (her and her sister's) after the marriage and finally she locates the act of buying the old shoes in a point of time earlier than the marriage. Interestingly, she uses negative form of being born (after we had not born). She does not say 'before we were born'. The use of after cannot be a simple confusion for before. If it were so, the utterance would be in the form of 'after we are born" but the structure the child constructs requires after in the context it emerges since the act of buying happens after the marriage in the Bergsonian time according to the 5-year-old. This linguistic encoding of time bears strong clues showing that 5year-olds conceive of the direction of time in the way it is depicted in Figure 2.

Along with temporal points, numbers which have temporal quality are also organized in a similar way by children.

(8)

\section{Şerife (06:10f)}

We were in our living room. Elif (08:09f) wanted to go to their room but was afraid because the corridor was dark. To Şerife:

Elif - Şerife could you please come along with me?

Şerife - Abla (addressing word), I used to go to that room on my own even when I was 5-4 years old.

After this talk, I tested Şerife:

Me - Şerife, do you remember the days your sister went to preschool?

Şerife - Yes, I remember.

Me - At what ages were you then?

Şerife - Wait, let me calculate... uhm.. 4- 3 years old.

(9)

Şerife (05:12f)

Şerife-Daddy, there was a cat downstairs, it will come again. Selen said so.

Me - Do you believe whatever Selen says?

Şerife - Yes I do, after yesterday, she had said 'It will come tomorrow' and it came yesterday as Selen had said.

Me - Yes, you are right.

The protocol (9) reflects that children possess an intricate organization of temporal points although their full conceptualization of time did not reach adult competency. In (9) the 5-year-old child locates future in the past just like the case in the celebrated 
movie Back to the Future. Yesterday is taken as the landmark temporal point. First, Selen's proposition about the cat's returning is placed as past for yesterday. Yesterday is the future for Selen's assumption but it is past regarding the time of the utterance by Şerife. Such complex structures emerging in a 5-year-old's speech makes one to ask the question whether we are assuming too little for this age group's conception of time.

In order to strengthen our qualitative findings related to the direction of time we tested children's conception of the direction of time using Figure 1 and instruction given in methodology part of the paper.

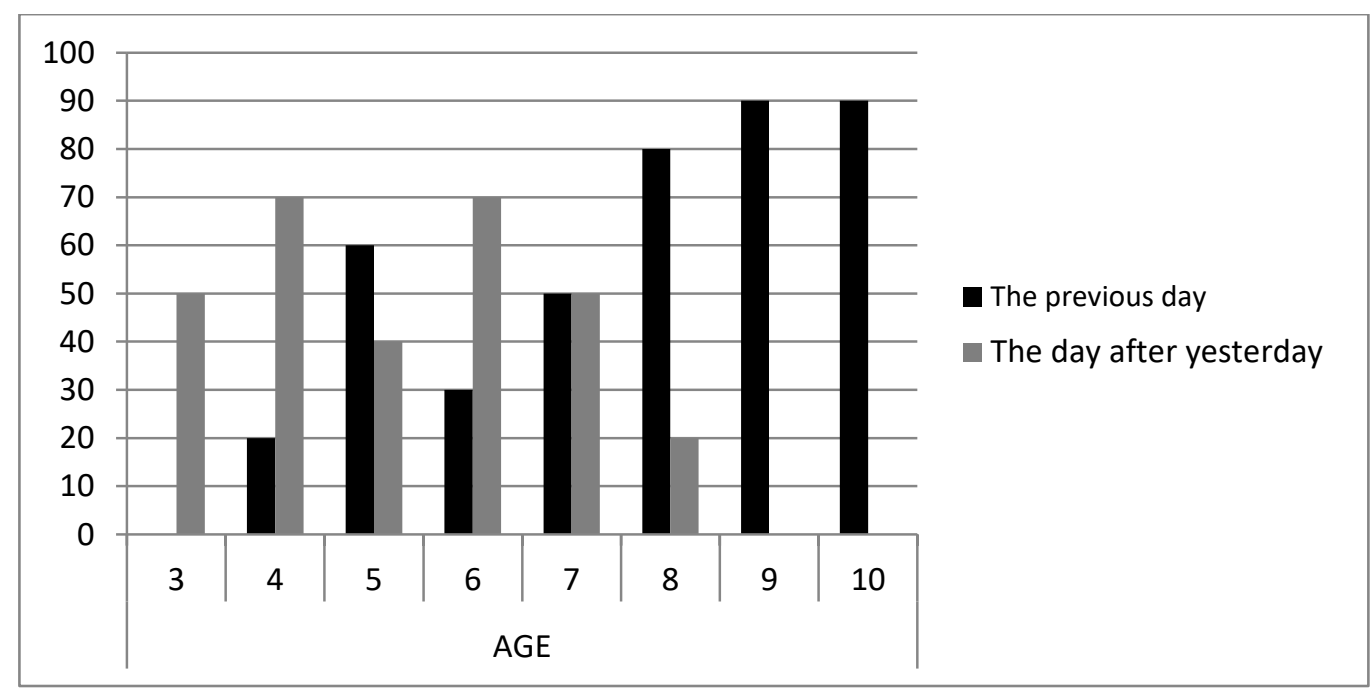

Figure 3: The distribution of children who named the previous day as 'the previous day' or 'the day after yesterday'

Children produced no data with reference to the direction of time while naming yesterday, tomorrow and the day after tomorrow. Some of the 3 and 4year-olds said "I don't know." when they are asked to name the box stands for the previous day and the day after tomorrow. Ten percent of the 9 and 10year-olds named the box for the previous day as 'the other day' where the other encodes no directionality. The reason why only $50 \%$ of the 3 year-olds named the previous day as the day after yesterday is because the rest of the 3-year-olds did not want to say anything for it. As Figure 3 shows, naming the previous day as the day after yesterday is decremental with increasing age where the age of 8 seems to be the turning point in this shift.

\subsection{Findings related to the duration and location of time}

The development of the conception of duration begins around the age of 15 months. My daughters used to be so happy when I appeared at the door when I came back from work. The sounds they produce, their desire to be held by me and the way they pressed themselves on my body showed that they were aware that I was away from their senses for a length of time which would make them so. I tested the impact of this disappearance and reunion by going outside the house secretly and waiting there for ten minutes and entering the house doing the same things I do when I come back home from work, they did not develop a reaction in the way they had done at the time my coming back from work. This observation implies that 15-month-old children possess a sense of duration which is not triggered by physiological needs such as feeding. This duration must have close relationships with expectation; expectation makes the duration sensible while duration increases the strength of expectation (Barnes \& Jones, 2000). Whether this relationship is primitive or derived is a question which needs to be investigated. Though the data are limited, they render some results related to the 
conception of duration (but not perception) in children regarding the Bergsonian time.

\section{(10)}

\section{Beril (05;04f)}

My wife would take Beril to a conference to be held at her school. Beril did not really want to go there. Beril- Mom, the thing we are going to watch will not last long, will it?

\section{Mother- No.}

Beril -How many meters does it take?

The protocol (10) implies that duration in Newtonian time is too abstract to be perceived for 5 -year-olds since it is not perceived in relation to a landmark event or state. Thus, the 5-year-old is trying to perceive it analogically by comparing it to visually perceptible length of meter instead of imperceptible length of mechanical time. The fallowing data demonstrate similar cases.

\section{(11)}

Nine o'clock in the morning. Şerife(05:03f) asks Elif (07:02f):

Şerife: Abla (Sister), you had said that we were going to play magician, but we did not.

Elif: Okay, let's do it today.

\section{Şerife: Is 'today' now?}

Elif: Yes.

Protocol (11) presents clues about the conception of Newtonian time divisions rather than duration. The 5-year-old children have the concept of day on the bases of circadian time. When they want to refer to the day three days later than today, the say "We will go to bed and get up, go to bed and get up, go to bed and get up and then go to granny's home".

A temporal point in a cyclic event such as a day is located temporally with reference to a relevant landmark event.

\section{(12)}

\section{Elif (07:01f)}

We are in my wife's school and waiting for someone. Elif asked:
Elif - Daddy, do you think you must have gone to school at this time?

Turkish. "Baba sen şimdi okul-a git-miş mi-sindir?"

Dad you now school-ACC. go-EVD. PAST QUST.2.Sing.-CERTAINITY

Me - Yes, long time ago.

Elif - Alas, I missed Marina. (Marina is a cartoon on TV.)

Protocol (12) demonstrates that the 7-year-old child constructs the temporal structure on the bases of circadian time. Another thing it shows is that the child's linguistic potential is ahead of her cognitive competence. Although the child cannot conceive of Newtonian temporal locations and duration, the complexity of the word 'git-miş-mi-sin-dir" shows that she grasped the linguistic composition of the time of an event with reference to another event. In this composition, she identifies my going to school as the landmark event by assigning a priority to it. She is also aware that the time of the utterance is close to the time of my leaving for work and the start of Marina; otherwise she would ask the same question even when it is evening time.

The following protocol reflects a similar case.

Şerife $(05 ; 03 \mathrm{f})$

Mother wanted to watch the movie Matilda but there was a power-cut. She was upset.

Şerife: Mom, do you like Matilda?

Mother: Yes.

(Turkish: Şerife. Sen onu hiç izlememiş miydin?)

Sen o-n-u hiç izle-me-miş mi-y-di-n?

You it-BUF.-ACC. Ever watch-NEG.-EV. PASTQUEST.-BUF.-PAST-2nd.Sing

Haven't you ever watched it?

It must be mentioned that while the focus of the protocol (12) is on time, the focus of (13) seems more on aspect in that the child is concerned with the occurrence of the act of watching Matilda: Has 
the mother watched it at least once in her life or not?

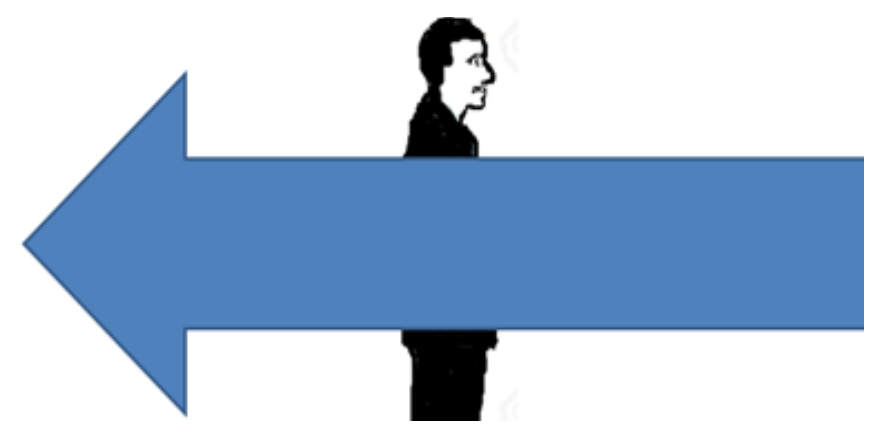

Figure 4: Bergsonian time for adults.

For adults, Bergsonian time runs from future towards past while we are located at one point in this river-like entity. It is always 'now'.

Protocol (14) reveals how children perceive Bergsonian time.

Şerife $(05 ; 03 f)$

- Dad, didn't you use to celebrate your brithday when you were a child?

- No.

- Then, how did you understand that you grew up?

The child is talking about a circannual event rather than a cercadian one. Circannual event (an event happening once in a year) is conceived as the result of the birthday party rather than being the cause.

The existence of Bergsonian understanding of time by children is reflected very clearly in the picture drawn and in the note taken by a Turkish-English bilingual 9-year-old boy (Figure 4).

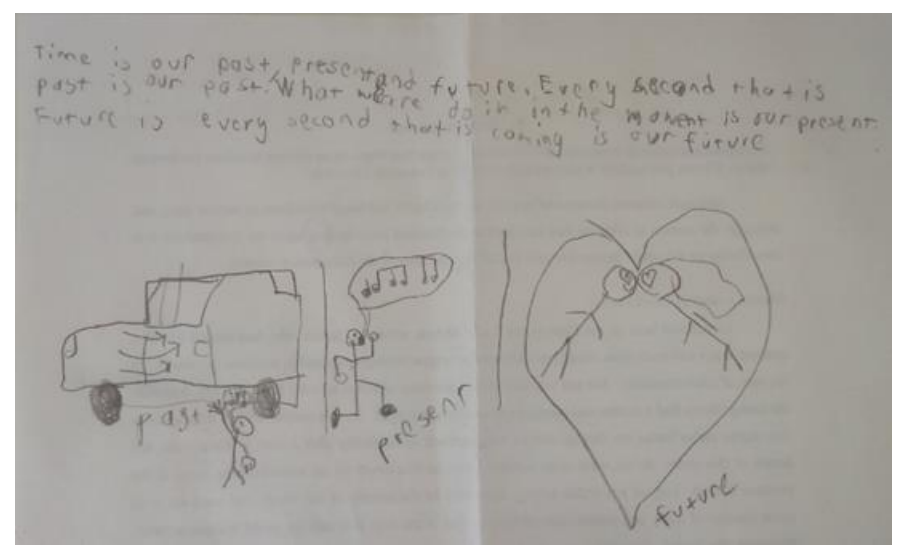

Figure 4: Reflection of the conception of Bergsonian time

The note reads as "Time is our past, present and future. Every second that is past is our past. What we are doing in the moment is our present. Future is every second that is coming is our future."

In this explanation, time is depicted as a river running pastward. The child is facing future; the closed door of the car (past), the dancing movement in the present (deictic now) and expectations (future) in the mind concretizes this flow.

\section{Conclusion and discussion}

The developmental processes of time in children are three fold: Circadian, Bergsonian and Newtonian time. Post-natal children construct a concept of time with sucking and feeding frequencies and this cyclic, circadian time is the basic time with which the child locates itself temporally. The improvement of general cognitive skills and the child's socialization process refine this circadian time conceptualization by adding priority, posteriority and sequentiality. By taking an event as the landmark, the child organizes all other events to construct her/his temporal schemata related to the schema of event/state groupings.

Although the observations in this study did not render sufficient data for generalization, we observed that children around the age of 15 months are aware of the duration of the disappearance of an entity for a while. Of course the relationship between the child and that entity is a significant factor in the awareness. Father, mother or other siblings are the ones who are in emotional relationship with the child. So, the emotional tie must have an impact on the expectations of the child. The awareness of disappearance and reunion sessions impose a type of time which is different from circadian time. While circadian time constructs temporal points and locations in the child, the durations construct the Bergsonian understanding of time. 
Our observations yielded data showing that children possess Bergsonian understanding of time around the age of 5 , scrutinizing experiments would reveal that it must emerge much earlier.

The occasional and longitudinal data produced by the researcher's three daughters show that time flows both pastward and futureward while it is pastward for adults. Along with our longitudinal observations, the test we administered to have an insight into the direction of time also demonstrates that young children conceive of the days in the past as temporal units (days) that are agglutinated one after the other towards past. Thus, the previous day for children turns out to be the day after yesterday and they apply the same agglutinating for futureward temporal units.

Our observational data shows that children around the age of 9 did not reach the adult competency in the grasp of Newtonian time. Newtonian time is totally fictional and thus abstract. It is clear that the grasp of duration in Newtonian time is very difficult even for adults. We cannot tell the duration if we do not consult the time measuring devices.

The previous literature does not present findings related to the conception of the direction of time. Other findings of this study are in line with findings in the previous literature.

Our study revealed that linguistic encoding of time is ahead of the concept of time in young children. Although the child did not attain some of the features of time in general terms, they are observed to construct sentences or phrases containing a very intricate organization of temporal points on the bases of priority, posteriority and sequentiality.

\section{References}

[1] Barnes, R. \& Jones, M. R. (2000). Expectancy, attention, and time. Cognitive psychology, 41, 254-311.

[2] Droit-Volet, S. \& Rattat, A. (1999). Are time and action dissociated in young children's time estimation? Cognitive development, 14, 573-595.

[3] Friedman, W. J. (1983). Image and verbal processes in reasoning about the months of the year. Journal of Experimental Psychology: Learning, Memory, and Cognition, 9, 650-666.

[4] Friedman, W. J. (1984). Analog and semantic models of judgments about the months of the year. Memory and Cognition, 12, 306-313.

[5] Glickman, G. (2010). Circadian rhythms and sleep in children with autism. Neuroscience and Biobehavioral Reviews, 34, 755-768.

[6] James, W. (1890). The principles of psychology (Vol. 1). New York: Holt

[7] Johnsson, A. (2008). Light circadian and circannual rhythms. In Espen Bjertness (Ed.) Solar radiation and human health. Oslo: The Norvegian Academy of Science and Letters.

[8] Jonas, K. J. \& Huguet, P. (2008). What day is today? A social-psychological investigation into the process of time orientation. PSPB, 34(3), DOI: 10.1177/0146167208317798

[9] Keil, F. C. (1984). Mechanisms of cognitive development and the structure of knowledge. In R. J. Sternberg (Ed.), Mechanisms of cognitive development (pp. 81-99). New York: Freeman.

[10] Koriat, A. \& Fischhoff, B. (1974). What day is today? An inquiry into the process of time orientation. Memory and Cognition, 2, 201205.

[11] Montangero, J. (1996). Understanding changes in time. The development of diachronic thinking in 7 and 12 year old children. London: Taylor \& Francis Inc. pp. 55-60.

[12] Myers, G. (1971). James on time perception. Philosophy of Science, 38(3), 353-360.

[13] Piaget, J. (1969). The child's conception of time. London: Routledge. 
[14] Rifkin, J. \& Howard, T. (1989). Entropy: Into the greenhouse world. New York: Bentam Books.

[15] Sauer, T. (2014). Piaget, Einstein, and the Concept of Time. In Jürgen Renn and Matthias Schemmel (Eds.) Culture and Cognition. Essays in Honor of Peter Damerow. Berlin:Edition Open Access,.

[16] Shanon, B. (1979). Yesterday, today and tomorrow. Acta Psychologica, 43, 469-476. 